\title{
Integration of Arrayed Waveguide Grating on Strip-Loaded Slot Waveguide for Sensing Applications
}

\author{
Janvit Tippinit*, Markku Kuittinen, and Matthieu Roussey \\ Institute of Photonics, University of Eastern Finland, P.O. Box 111, 80101 Joensuu, Finland
}

\begin{abstract}
We demonstrate the integration of arrayed waveguide grating (AWG) de-multiplexer with a low loss and low index contrast platform, i.e., a striped-loaded slot waveguide (SLWG). The SLSW-AWG is designed to operate around the wavelength $\lambda=1550 \mathrm{~nm}$ with a four-output channel. The device experiences excellent output parameters: channel width $\delta \lambda=1.39 \mathrm{~nm}$ at $-3 \mathrm{~dB}$, channel spacing $\Delta \lambda=2.43 \mathrm{~nm}$ and extinction ratio $E R=9.87 \mathrm{~dB}$, useful for sensing applications.
\end{abstract}

\section{Introduction}

Arrayed waveguide grating (AWG) is one of the most important integrated photonic devices in telecom and sensing systems. This device can be used as wavelength multiplexers and de-multiplexers, combining several wavelengths or separating them to a single wavelength. The major problem of AWGs, however, is optical insertion losses, originating mainly from the field mismatch due to the high refractive index difference between the waveguide structures and the surrounding. This is enhanced by the sidewall roughness, as it can be seen with, e.g., silicon ( $\mathrm{Si})$ and silicon nitride $\left(\mathrm{Si}_{3} \mathrm{~N}_{4}\right)$ on silicon dioxide $\left(\mathrm{SiO}_{2}\right)$ waveguides [1-2]. To overcome the loss due to the sidewall roughness, a very near-infrared ( $\sim 900 \mathrm{~nm}) \mathrm{Si}_{3} \mathrm{~N}_{4}$ AWG has been demonstrated using a double etch step, which applied at the access waveguides near star couplers and the bends in the arrayed waveguides, reducing the index contrast [3].

We propose another approach, which uses a novel waveguide structure, so-called striped-loaded slot waveguide (SLSW). This waveguide is constituted of a horizontal slot waveguide, a layer of low index material $\left(n_{\mathrm{L}}\right)$ between two layers of higher index material $\left(n_{\mathrm{H}}\right)$, and a polymer strip on the top, inducing the refractive index difference locally in the slot waveguide. The strong confinement of the electric field of the mode occurs in the $n_{\mathrm{L}}$ region, located underneath the etched polymer strip. This makes the waveguide perfect for integrated devices since the structures can be patterned directly on the polymer and not on the guiding layer. There is a very limited interaction of the optical field and the sidewall roughness of the strip. SLSW has been, moreover, integrated with some nano- and microstructures such as $\mathrm{Y}$-junctions, ring resonators, and photonic-crystal-based structures [4-5]. In this paper, we design an AWG on SLSW structure at the center wavelength of $1550 \mathrm{~nm}$ for sensing application, and to the best of our knowledge, no SLSW-AWG has been reported yet.

\section{Methodology and results}

The optical loss is one of the main concerns in photonic devices, and SLSW has a great advantage in reducing the loss due to the sidewall roughness. For operation $\lambda=1550$ $\mathrm{nm}$, the waveguide consist of two $\mathrm{TiO}_{2}$ slab waveguides $\left(n_{\mathrm{TiO} 2}=2.27\right)$ with the height of $h_{1}=200 \mathrm{~nm}$ and $h_{3}=180$ $\mathrm{nm}$, and $\mathrm{a} \mathrm{SiO}_{2}$ slab waveguide $\left(n_{\mathrm{SiO} 2}=1.44\right)$ with the height $h_{2}=80 \mathrm{~nm}$ in between. On the top of these layers, polymer $\left(n_{\text {Polymer }}=1.60\right)$ is deposited with a height of 250 $\mathrm{nm}$, and the polymer strip waveguide is patterned with a width of $1.2 \mu \mathrm{m}$. This structure provides the strong optical confinement for TM polarization in the $\mathrm{SiO}_{2}$ layer [6], as shown in figure 1 .

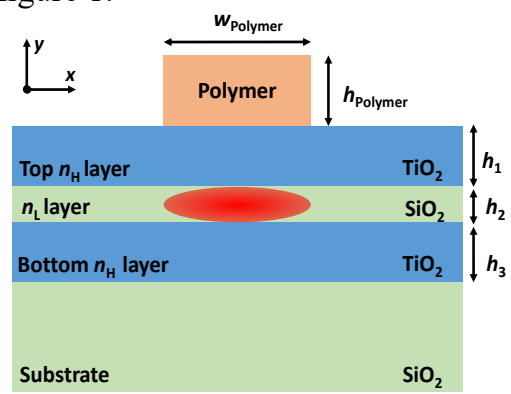

Fig. 1. Schematic of cross-section of a SLSW.

Table 1. Design parameters.

\begin{tabular}{|l|c|c|}
\hline \multicolumn{1}{|c|}{ Parameter } & Notation & Value \\
\hline Number of array waveguides & $N$ & 22 \\
\hline Diffraction order & $m$ & 102 \\
\hline Output waveguide separation & $D$ & $6.48 \mu \mathrm{m}$ \\
\hline Array waveguide separation & $\Lambda$ & $6.48 \mu \mathrm{m}$ \\
\hline Focal length & $f$ & $352.62 \mu \mathrm{m}$ \\
\hline Length increment & $\Delta L$ & $77.114 \mu \mathrm{m}$ \\
\hline
\end{tabular}

* Corresponding author: janvit@uef.fi 


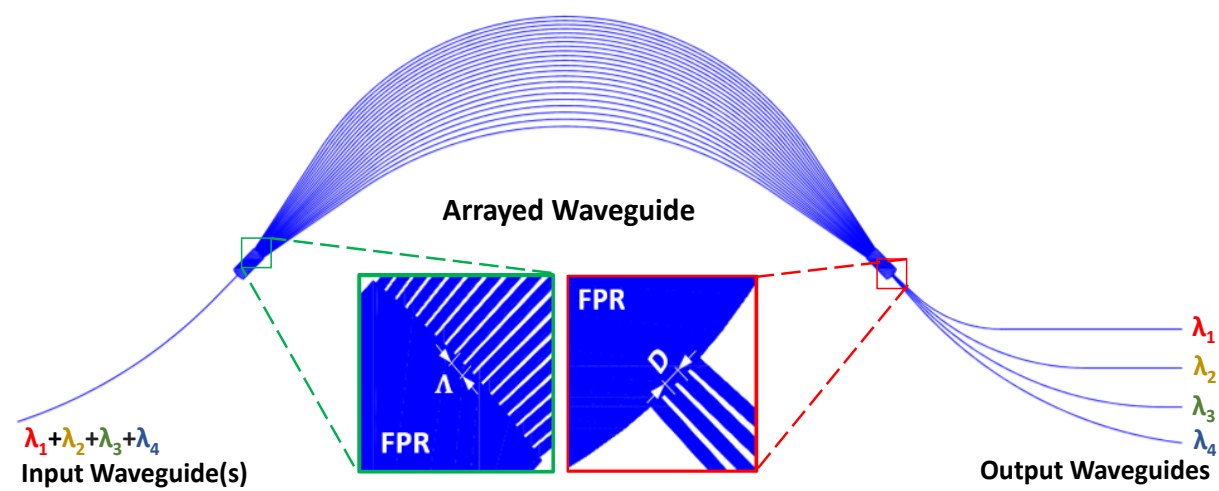

Fig. 2. Schematic of the SLSW-based AWG device.

We employ a beam propagation method (BPM) to design the SLSW-AWG device. The polymer strip waveguide on the top of the sandwich layer of $\mathrm{TiO}_{2}$ and $\mathrm{SiO}_{2}$ causes slightly higher in the effective index of the core $\left(n_{\text {eff,core }}=\right.$ $2.03)$ than of the cladding $\left(n_{\text {eff,clad }}=1.99\right)$. We design the device with the parameters listed in table 1, and the entire geometry is depicted in Fig. 2.

Figure 3 shows the normalized power spectrum at the output of each channel. We obtain a channel width $\delta \lambda=$ $1.39 \mathrm{~nm}$ at $-3 \mathrm{~dB}$ and a channel spacing $\Delta \lambda=2.43 \mathrm{~nm}$. The extinction ratio, $E R=9.87 \mathrm{~dB}$, is sufficient to obtain wellseparated channels. The proposed device is capable to perform a four-wavelength de-multiplexer with a wide channel spacing as well as with the excellent extinction ratio. This makes the device suitable for sensing applications.

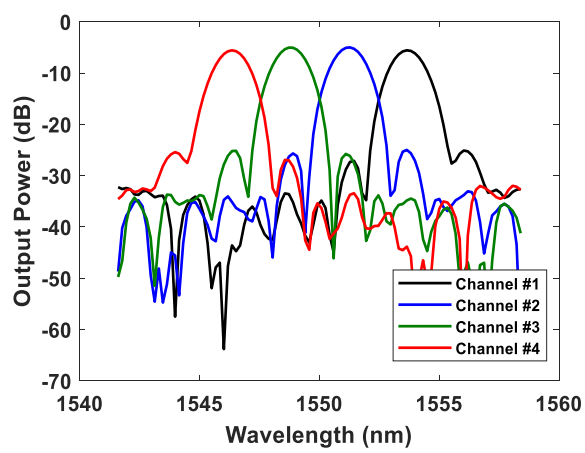

Fig. 3. Spectrum at each output of the device.

\section{Conclusions}

We have succeeded to design an SLSW-based AWG device, which operates at the center wavelength of 1550 $\mathrm{nm}$. The device is capable of de-multiplexing four wavelengths with a separation of $2.43 \mathrm{~nm}$. We obtain the channel width at $3 \mathrm{~dB}$ of $1.39 \mathrm{~nm}$ and well-separated output spectra with the extinction ratio of $9.87 \mathrm{~dB}$.

\section{References}

1. D. Dai, Z. Wang, J.F. Bauters, M.-C. Tien, M. J. R. Heck, D.J. Blumenthal, J.E. Bowers, Opt. Express 19, 14130-14136 (2011)

2. P. Dumon, W. Bogaerts, D.V. Thourhout, D. Taillaert, R. Baets, J. Wouters, S. Beckx, and P. Jaenen, Opt. Express 14, 664-669 (2006)

3. D. Martens et al., in IEEE Photonics Technology Letters, 27(2), 137-140 (2015)

4. M. Roussey, L. Ahmadi, S. Pélisset, M. Häyrinen, A. Bera, V. Kontturi, J. Laukkanen, I. Vartiainen, S. Honkanen, M. Kuittinen, Opt. Lett. 42, 211-214 (2017)

5. S. Pélisset, M. Roussey, J. Eur. Opt. Soc. - Rapid Publ. 15, 6 (2019).

6. S. Pélisset, J. Laukkanen, M. Kuittinen, et al, J. Eur. Opt. Soc. - Rapid Publ. 13, 37 (2017) 